\title{
A Network Flow Model for Determining the Safe Evacuation Plan of a Public Building
}

\author{
P.K. Yadav ${ }^{*}$, Nadeem Ahamad and R.K. Sharma \\ CSIR-Central Building Research Institute, Roorkee-247667
}

\begin{abstract}
Emergent evacuation in buildings becomes necessary in case of an accident such as fire, earthquake, toxic gas release etc. Bomb threat also makes it prudent for the occupants to escape out in a minimum possible time. Emergent evacuation is possible when minimum but adequate numbers of escape routes are available to the occupants for efficient movement and rapid evacuation. Inadequate size of routes creates bottlenecks and backtracking that may cause stampede, crushing and trampling. Therefore, it is imperative to examine the building design with respect to numbers \& size of exits, stairwells and other substantial features of the building egress plan. Planning of the movement of people is of great importance to the safety measures. Therefore, the systematic scheduling for exit of occupant inside the building is the fundamental requirement for efficient evacuation to minimize the loss of life and avoiding the congestion, backtracking and circling. In this direction, many mathematical models have been developed to compute the evacuation time. In CBRI, attempts have been made to compute the possible time of evacuation with adequate number of escape routes of adequate size to avoid stampede, crushing and trampling. In this paper the attention has been drawn on the rapid evacuation of a building without bottlenecks in the escape routes. The model discussed here based on graph theoretical approach considering the parameters like Dynamic Capacity (DC) and Traversal Time Step (TTS) of each evacuation path. The waiting time for each path has also been minimized using queuing theory. For optimal utilization of paths, the service rate, throughput and response time of each path has also been considered.
\end{abstract}

Keywords: Evacuation, Escape Route, Egress, Network, Optimization, Mathematical Modeling

\section{Introduction}

There are a number of reasons for which emergency evacuation becomes necessary. Apart from fire and smoke threat, others may include the threat of an earthquake, at toxic gas leak, a power failure, a bomb threat, and a civil defence emergency. Such incidents or even simple exuberance of some members of a crowd may lead to serious injuries to the people. People may be killed due to crushing or trampling. Serious injury and even death can occur during entry, occupancy and evacuation of a building. Such events can also occur, during sports events, virtuous congregation, music chorus, cinema hall and similar gatherings. Examples of tragic outcome such as in Uphar Cinema fire on June 13, 199759 people were died, on April 10, 2006 in Meerut, fare fire in which more than 50 people were killed and more than 100 were injured are closely linked with the flow of people with jams and congestion. Some other examples of tragic consequences in which hundreds of people were killed are closely linked with the flow of people with jams and congestion e.g. in Kumbakonam on 16th July 2004, 83 children killed in school fire and on 3rd February 2004, Srirangam wedding tragedy, which cost 62 lives because of fire accident in the marriage hall, on 22nd May 2005, bomb explosions rocked two cinema halls in Delhi injuring at least 40 people. Therefore, for efficient movement and rapid evacuation of a building sufficient numbers of escape-routes is the priori requirement. Flow of occupants through various paths available inside the building is directly associated with the complexity of the evacuation process. In literature several methods and algorithms are now available to analyze the problem related to evacuation. Mathematical modeling plays an important role to predict the number of paths available within the building and the flow of occupants through identified paths so that planning of a building may be done accordingly.

Evacuation modeling problems in buildings is a field of interest for many researchers who developed different models to evaluate the performance of evacuation process. Chalmet, Francis \& Sanders, [2] have reported a Network Models for Building Evacuation. A lot of work have been reported in the literatures by the researches in this area and published in the form of different government reports. In 1984 a research report on the evacuation problem by applying a negative exponential was published by Francis, R. L., and Chalmet, L. G. [3]. A computer program to determine optimal building evacuation plans, EVACNET+ has been developed by Kisko, T. M., and R.L. Francis [4]. Roytman [5] have prepared the fire safety standards for building construction. In the Soviet Union; Predtetschenski and Milinski [6] explored the same evacuation problems related to civilian facilities. Gupta A.K. \& Yadav, P.K. [7] have developed a Model SAFE-R to study the evacuation profile of a Building during an emergency. Gupta, A.K. Yadav, P.K. \& Sharma, R.K. [8] have developed an evacuation model for evacuation management in high rise building. Francis, R. L. and Chalmet, 
L.G. $[9,10]$ have designed a prototype primer software system for building evacuation by using the network modeling technique. Software for the fire auspices community was published in NFPA Journal by Pucci, W. E. [11]. Fahy [12] presented EXIT89 model to study the evacuation process in high-rise buildings. EXIT89 also requires network description of the building in the form of nodes and arcs. Thompson and Marchant [13-15] developed a model SIMULEX to evaluate the potential evacuation process of a complex building with a high degree of accuracy. In the development of SIMULEX, the authors have attempted to minimize user inputs while increasing the complexity of the algorithm in the program. The program modulate route-finding techniques so that travel distance can be calculated automatically.

Hagiwara and Tanaka [16] have investigated the existing provisions of means of escape or escape routes in various countries. It is noted that the maximum limit of 2.5 minute of escape time has no engineering or scientific basis. So is the case of maximum travel distance between 40-60 m. Berlin et al. [17] also presented a methodology for estimating the evacuation time from a building. Network descriptions of the building together with a simulation model of occupant movement are used to simulate alternative egress and rescue plans from group houses. Technique for calculating the available number of direct routes from any room to any location of safety has also been suggested.

The model discussed in this paper is to determine the systematic scheduling for exit of person without congestion, backtracking and circling to minimize the loss of life. The 'depth and breathe search technique' of graph theory has been used to identify various routes available to the occupants for movement. The proposed methodology is expected to be useful to plan the minimum number of escape routes, their capacities, and travel distances.

The increasing complexity of various real life problems results in greater demand for faster computer components. One of the approaches to meet this growing demand is the use of parallel processing. An alternative and closely related to parallel computers is the concept of DRTS. Distributed real time system is a computer system in which multiple processors connected together through a high-bandwidth communication link. These links provides a medium for each processor to access data and programs on remote processors.

A user-oriented definition of distributed computing is reported by $[1,2]$ that " The Multiple Computers utilized cooperatively to solve problems i.e. to process and maintained the large scale database of the programs which are to be executed on these type of computing environment". The assignment of task to processors is an essential step in exploiting the capabilities of a DRTS and may be done in a variety of ways (i) Static Allocation and (ii) Dynamic Allocation. In static allocation, when a task is assigned to processor, it remains there while the characteristic of the computation change and a new assignment must be computed. These problems may be categorized in static [3-10]. In order to make the best use of resources in a distributed real time computing environment, it is essential to reassign the tasks dynamically during program execution, so as to the benefit of changes in the local reference patterns of the program [11-18]. Although the dynamic allocation has potential performance advantages, Static allocation is easier to realize and less complex to operate.

Several other methods have been reported in the literature, such as, Integer programming [19, 21], Branch and bound technique [22-23], Matrix reduction technique [7], and reliability evaluation to deal with various design and allocation issues in a DRTS by [24-30]. In this paper we introduce an algorithm which performs static allocation of such program tasks in a heterogeneous DRTS to minimize the application program's Parallel Processing Cost with the goal to maximize the overall system throughput and allocated load on all the processors should be approximately balanced. Because strictly balanced load distribution may not be possible to achieve, a system is considered to be balanced if the load on each processor is equal to the average load, within a reasonable tolerance. A tolerance of $10-15 \%$ of average load is generally chosen. We assume that the number of program modules is much larger than the number of processors, so that no processor remains idle. Several sets of input data are considered to test the efficiency and complexity of the algorithm. It is found that algorithm is suitable for arbitrary number of processors with the random program structure and is workable in all the cases.

\section{Definitions}

Nodes and Edges: The building is described with the help of a network. The network consists of a set of nodes connected by edges. Nodes are used to define the building spaces, such as rooms, corridors, stairs, halls etc. The edges represent the travel paths between two nodes. An edge is the passageway through which occupants traverse.

Node Capacity (NC): The number of person that can be accommodated on a particular node is known as Node Capacity.

Traversal Time (TT): Traversal time is an amount of time, which is required to cover an edge length. Traversal time is obtained by dividing edge length with the average walking speed of the occupants. The extent of traversal time depends upon the age, sex, profession and climate besides number of people in the streams. The speed reduces to $50 \%$ while assisting others and by $40 \%$ during crawling. The most convenient form of 
representing traversal time is the Time Periods (TP) of fixed length say five seconds which is called Traversal Time Step (TTS). A travel time of fifteen seconds would mean three TTS.

Dynamic Capacity (DC) - Dynamic Capacity is the number of people that can flow through an edge in a given time. DC is represented in the form of number of people moving per unit time period. Fruin's [1] has given an account of the levels of services to determine the values of DC for different type of arcs, viz., horizontal passages, doors and stairs.

Travel Path - Travel path is a combination of several arcs/ branches together. The starting node of a travel path is known as the source node and ending node is known as an exit node.

Escape Route - An escape route is defined as sequence of connected spaces starting with the source node and ending with a designated location of safety i.e. exit node.

\section{Problem Statement}

The systematic flow of occupants inside a building is the fundamental requirement for safe evacuation. While defining safe escape routes, backtracking and circling are not allowed i.e. the occupants are prohibited to turn around or passing through the same node more than once. The restrictions on backtracking and circling are applied by invoking the assumption that the occupants are familiar with the building and they are aware of the pre-decided optimal evacuation plan. While there are several components related to the egress problem, we are primarily converted with the adequacy of the number of exits, their capacity and sizes requiring minimum possible time of evacuation.

1. The proposed methodology includes:

2. Determination of the service rate and service time for each edge

3. Calculation of Node capacity of each Node

4. Determination of dynamic capacities of each edge

5. Calculation of total TTS of each edge

6. Identification of paths for each source node

7. Arranging paths in ascending order in terms of their Cumulative Service Rate (CSR)

8. Identification of activated paths and there capacity

9. Determination of minimum required TTS to evacuate the building

10. Calculation of total number of evacuees passing though each activated path

11. Computation of evacuees moving per TTS for each activated path

12. Computation of the utilization of paths w. r. t. the following

I. throughput,

II. expected number of occupants in the activated path

III. expected queue lengths of the occupants passing through the activated paths

IV. mean waiting time of the occupants in the queue and expected waiting time of the persons in all activated paths queue

\section{Proposed Method}

The proposed model requires the network description of the building plan having a set of "n" nodes connecting "m" edges. A graph matrix $G(i, j), i=1,2, \ldots . m$ and $j=1,2 \ldots 4$ has been formulated, the first column of the matrix represents the edge number, whereas the second and third columns represent the node numbers on which the edges are connected. The fourth column denotes the type of edge i.e. whether the branch directed or undirected define as 1 and 0 respectively. Each edge has its own weights $(\mathrm{c}, \mathrm{t})$ where "c" represent the dynamic flow capacity and " $\mathrm{t}$ " represent the number of time steps required to pass the flow capacity " $\mathrm{c}$ " through the mth edge.

To determine the Node Capacity (NC), Predtechenskii, V.M. and Milinskii, A. [6], have suggested taking the horizontal projection of a person as an ellipse whose axis corresponds to the width and breath of the person. The actual shape of the horizontal projection of a person at chest level differ slightly from ellipse, however, the variety of physique and cloths, this distortion can be neglected. Author also suggested the width a $=0.5 \mathrm{~m}$ and thickness $\mathrm{c}=0.32 \mathrm{~m}$ for an adult in winter street dress. The horizontal projection $\mathrm{f}=\frac{\pi}{4 \mathrm{ac}^{2}}$ for a person is 0.126 and the number of person $/ \mathrm{m}^{2}$ can be computed by $\mathrm{N}=\frac{\mathrm{D}}{\mathrm{f}}$ where $\mathrm{D}$ is the flow density expressed as the sum of the horizontal projection of the people in the area occupied by the flow. The physical limit of the density $\mathrm{D}=0.20$ to 0.40 . In the present study the value of $\mathrm{D}$ is 0.25 have been taken to determining value of persons/ $\mathrm{m}^{2}$. Substituting the value of " $\mathrm{D}$ " and " $\mathrm{f}$ ", we get the value of $\mathrm{N}=2$. The capacity of the node is calculated by using equation (1).

$\mathrm{NC}=\mathrm{N} \times \mathrm{U}_{\mathrm{fa}}$ 
Where $\mathrm{U}_{\mathrm{fa}}$ is the Usable Flore Area within a Room

In the present study the Ufa, which is approximately $60 \%$ of available corridor area and $30 \%-60 \%$ in case of rooms/halls, and stairwell has been assumed. Building code have specified a unit of exit width as 0.533 $\mathrm{m}$, which is based on the Discharge Rate (DR) of 40 persons in 60 seconds or expressed as the DR of 100 persons in 150 seconds which relates to evacuation time. However, a width of $0.533 \mathrm{~m}$ is not acceptable in practice because it is dangerous, and the minimum width of $0.756 \mathrm{~m}$ has been taken to provide the DR of 40 persons in 60 seconds for developing the model. Based on these assumptions it is found that the 52 person discharges in $1 \mathrm{~m}$ width and the discharge time of 1 person is 0.867 second. It has been observed that the percentage use of actual width is not constant It can be depends upon the condition type of the building components while discharging the occupants is assumed as Effective Width (EW). The value of the DR can be computed by using the equation (2) and the DC and TTS of each edge are calculated by using equations (3) and (4) respectively:

$\mathrm{DR}=0.867 \times$ Effective Width $(\mathrm{EW})$

$\mathrm{DC}=\mathrm{DR} \times \mathrm{Time}$ period $(\mathrm{TP})$

$$
\text { TTS }=\frac{\text { Traval Distance of the Branch }}{\text { Average Speed of the Person } \mathrm{x} \text { TP }}
$$

Assuming the value of one $\mathrm{TP}=5$ seconds

The service rate " $\mu_{\mathrm{m}}$ " will be the ratio of "t" and "c" and the service time will be the reciprocal of " $\mu_{\mathrm{m}}$ " for the mth edge. The total number of available paths have been calculated by applying "depth and breathe search technique" of graph theory. The "CSRi" and Minimum Flow Capacity "MFCi" of each ith path has been calculated using equations (5) and (6).

$$
\begin{aligned}
& \mathrm{CSR}_{\mathrm{i}}=\sum\left\{\left(\mu_{\mathrm{m}}\right): \mathrm{m}^{\text {th }} \text { edge blong to } \mathrm{t}^{\text {th }} \text { path }\right\} \\
& \mathrm{MFC}_{\mathrm{i}}=\min \left\{\mathrm{c}: \mathrm{c} \text { is the DC of the } \mathrm{m}^{\text {th }} \text { edge of the } \mathrm{i}^{\text {th }} \text { path }\right\}
\end{aligned}
$$

Paths are arranged in ascending order for their CSR assuming that all the paths are activated initially. The activated paths and their MFC are determined by using the algorithm given below:

Paths Activation Algorithm (PAA):

Step-1: Calculate the capacity MFCi of each path and store in a linear array MFC ( ).

Step-2: Calculate CSR of each path and store in a linear array CSR ( ).

Step-3: Sort the paths in increasing order of their CSR \& store them in a linear array $\mathrm{P}_{\text {path }}($ )

Step-4: Select the first path (say pi) from $\mathrm{P}_{\text {path }}($,).

Step-4.1: Select $\mathrm{MFC}_{\mathrm{i}}$ to path pi and store this in a linear array $\mathrm{C}_{\text {assign }}($,$) .$

Step-4.2: Store the path pi in a linear array $\mathrm{P}_{\text {act }}()$

Step-4.2: Modify the $\mathrm{MFC}_{\mathrm{i}}$ for remaining paths having at least on common edge with path $\mathrm{p}_{\mathrm{i}}$ by subtracting the $\mathrm{MFC}_{\mathrm{i}}$

Step-4.3: Modify $\mathrm{P}_{\text {path }}\left(\right.$ ) by removing the path $\mathrm{P}_{\mathrm{i}}$

Step-4.4 Select paths whose $\mathrm{MFC}_{\mathrm{i}}$ becomes zero and remove from $\mathrm{P}_{\text {path }}()$

Step-5: If Ppath ()$\neq\{\}$ then repeat the steps-4 else go to step-6

Step-6: Stop.

If " $\mathrm{T} j$ " is the total TTS required for evacuating the $\mathrm{N}$ occupants from the $\mathrm{j}^{\mathrm{t} \text { s }}$ source node and if there are " $\mathrm{k}$ " number of activated paths in the jth source node then the number of evacuees " $\mathrm{p}_{\mathrm{i}}$ " moving through each $\mathrm{i}^{\text {th }}$ activated paths may be calculated using equation (7).

$$
\mathrm{p}_{\mathrm{i}}=\operatorname{MFC}_{\mathrm{i}}\left[\mathrm{T}_{\mathrm{j}}-\left(\sum \mathrm{TTS}_{\mathrm{i}}-1\right)\right]
$$

Where $\mathrm{i}=1,2,3, \ldots \ldots \ldots \ldots \ldots . . . \mathrm{k}$ 
Where MFCi and $\sum \mathrm{TTS}_{\mathrm{i}}$ are the minimum flow capacity and TTS required for the $\mathrm{i}^{\text {th }}$ activated path respectively. Since "N" number of evacuees shall have to evacuate through " $k$ " activated paths of the $\mathrm{j}^{\text {th }}$ source node in $\mathrm{Tj}$, therefore, we can represent this relation as equation (8).

$$
\sum_{\mathrm{i}=1}^{\mathrm{k}} \mathrm{p}_{\mathrm{i}}=\mathrm{N}
$$

Solving equations (7) and (8), we will get the value of pi and $\mathrm{Tj}$.

The paths utilizations i.e. throughput $\mathrm{TP}_{\mathrm{i}}$ for all activated paths has been determined using equation (9).

$$
\mathrm{TP}_{\mathrm{i}}=\left(\frac{\mathrm{p}_{\mathrm{i}}}{\mathrm{T}_{\mathrm{j}}}\right), 1=1,2,3 \ldots \ldots \ldots \ldots \mathrm{k}
$$

Assuming that, all " $\mathrm{k}$ " active paths are independent and follow the $\mathrm{M} / \mathrm{M} / 1$ queuing system. The service rate $\mu \mathrm{i}$ of the ith-activated path will be the $\mathrm{MFC}_{\mathrm{i}}$ of the paths. The arrival rate $\lambda_{\mathrm{i}}$ will be the reciprocal of the $\mathrm{CSR}_{\mathrm{i}}$ of the paths. Occupants shall arrive independently at each node of the activated paths and join the queue. The queuing discipline at all the nodes will follow the pattern FIFO (first in first out). From this queue system, the expected number of occupants, expected queue length, mean waiting time and other parameters have been computed. The expected number of occupants $\mathrm{L}_{\mathrm{n}, \mathrm{i}}$ in the $\mathrm{i}^{\text {th }}$ activated path, has been calculated using equation (10).

$$
\mathrm{L}_{\mathrm{n}, \mathrm{i}}=\frac{\lambda_{\mathrm{i}}}{\left(\mu_{\mathrm{i}}-\lambda_{\mathrm{i}}\right)}, \mathrm{i}=1,2,3 \ldots \ldots \ldots \mathrm{k}
$$

The expected queue length, $\mathrm{L}_{\mathrm{q}, \mathrm{i}}$ of the occupants passing through the $\mathrm{i}^{\text {th }}$ activated path has been calculated using equation (11).

$$
\mathrm{L}_{\mathrm{q}, \mathrm{i}}=\frac{\lambda^{2}}{\mu(\mu-\lambda)}, \mathrm{i}=1,2,3 \ldots \ldots \ldots \mathrm{k}
$$

The mean waiting time, $\mathrm{W}_{\mathrm{n}, \mathrm{i}}$ of the occupants in the queue of the $\mathrm{i}^{\text {th }}$ activated path in the building network has been calculated using equation (12).

$$
\mathrm{W}_{\mathrm{n}, \mathrm{i}}=\frac{\lambda}{\mu(\mu-\lambda)}, \mathrm{i}=1,2,3 \ldots \ldots \ldots \mathrm{k}
$$

The expected waiting time, Ws,i of the persons in the ith activated path queue network in the building network has been calculated using equation (13).

$$
\mathrm{W}_{\mathrm{q}, \mathrm{i}}=\mathrm{W}_{\mathrm{n}, \mathrm{i}}+\frac{1}{\mu_{\mathrm{i}}}=\frac{1}{\mu-\lambda}, \mathrm{i}=1,2,3 \ldots \ldots \ldots \mathrm{k}
$$

\section{Implementation Of The Model}

To justify the application and usefulness of the present model, an example of a two storied public building which may be control room in an industry, a court room, a bank or a similar mercantile building, a cinema hall or similar entertainment hall, or even a religious congregation is depicted in Fig. 1. It is assumed that the total 142 people are assembled in the building.

There are 72 peoples are present at ground floor in Room and 70 occupants are at first floor in two rooms (35 in each room). There are two exits of different capacity are available. The network representation of the building is depicted in Fig. 2. The network comprises a set of " $\mathrm{n}=14$ " nodes connected through " $\mathrm{m}=18$ " edges. The nodes of the network represent the source space i.e. room, hall, corridor and stair well etc., where occupants can congregate. The edges represent the path joining the two nodes. Each edge has its own weights $(c, t)$ where "c" represent the dynamic flow capacity and " $t$ " represent the number of TTS required to pass the flow capacity "c" through the edge. 


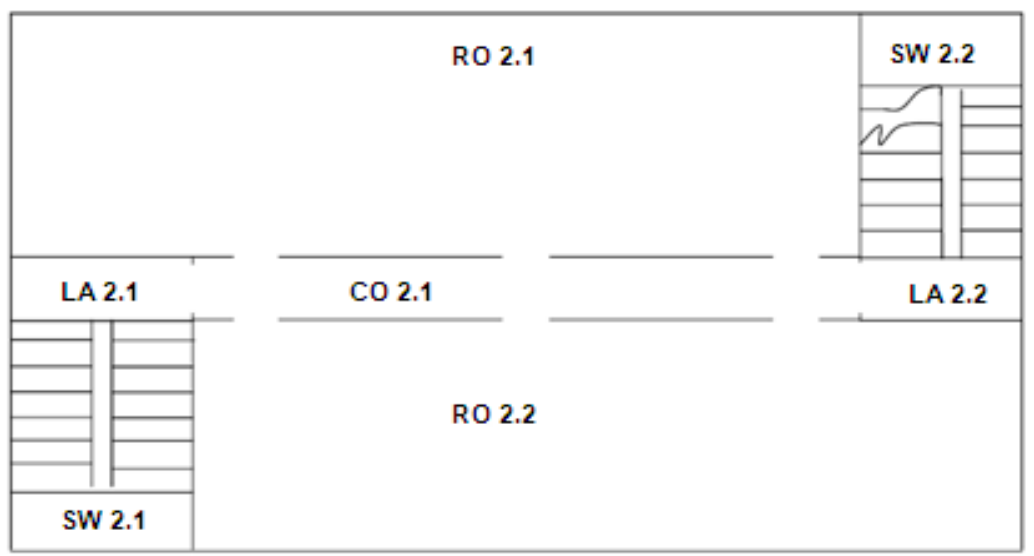

FIRST FLOOR PLAN

DO 1.1

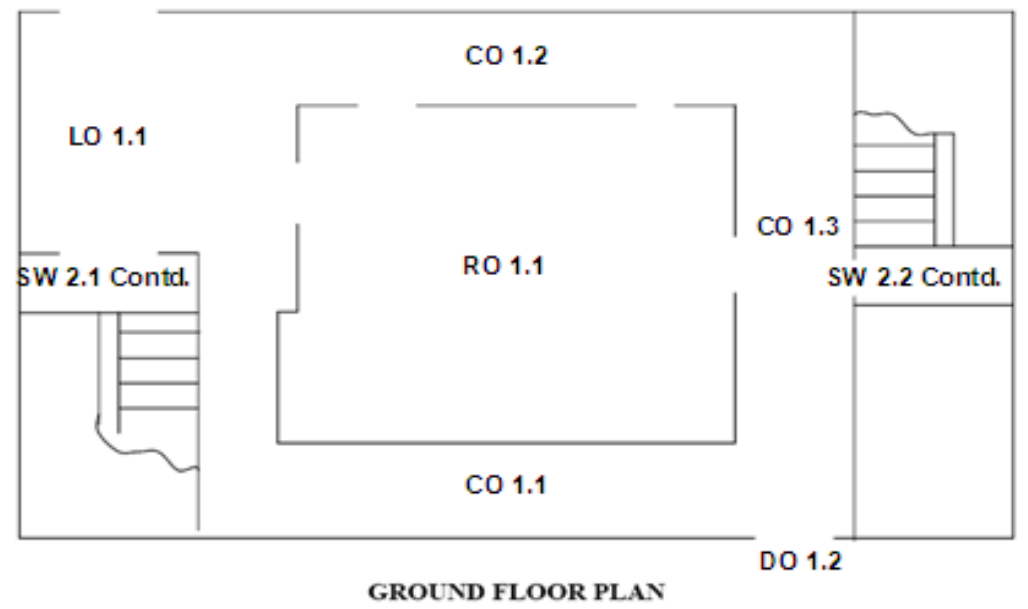

Fig. 1 Layout plan of the example building

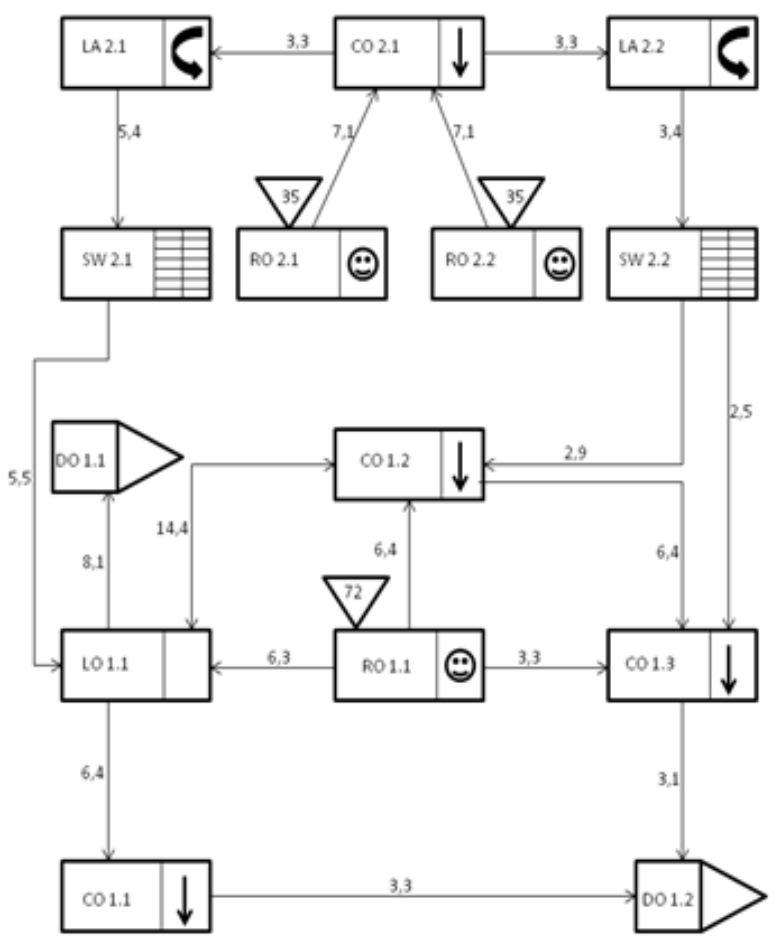

Fig. 2 Network representation of the example building 
The node capacities have been calculated using the equation (1) and the Initial Content (IC), i.e. the number of persons occupying at the node are given in Table 1.

Table 1

\begin{tabular}{|c|c|c|c|c|c|}
\hline Sl. No & Node Name & Total Floor Area $\left(\mathrm{m}^{2}\right)$ & $\begin{array}{c}\text { Usable Floor } \\
\text { Area }\left(\mathbf{U}_{\mathrm{fa}}\right)\left(\mathrm{m}^{2}\right) \\
\end{array}$ & $\begin{array}{c}\text { Node Capacity (NC) } \\
\text { (Persons) }\end{array}$ & $\begin{array}{c}\text { Initial Content } \\
\text { (IC) }\end{array}$ \\
\hline 1 & RO 1.1 & 166.50 & 108.23 & 216.45 & 72 \\
\hline 2 & LO 1.1 & 56.35 & 45.08 & 90.16 & \\
\hline 3 & $\mathrm{CO} 1.1$ & 67.50 & 47.25 & 94.50 & \\
\hline 4 & $\mathrm{CO} 1.2$ & 58.50 & 40.95 & 81.90 & \\
\hline 5 & $\mathrm{CO} 1.3$ & 13.50 & 9.45 & 18.90 & \\
\hline 6 & SW 1.1 & 33.75 & 16.88 & 33.75 & \\
\hline 7 & SW 1.2 & 22.50 & 11.25 & 22.50 & \\
\hline 8 & RO 2.1 & 162.00 & 105.30 & 210.60 & 35 \\
\hline 9 & RO 2.2 & 135.00 & 87.75 & 175.50 & 35 \\
\hline 10 & $\mathrm{CO} 2.1$ & 67.50 & 47.25 & 94.50 & \\
\hline 11 & LA 2.1 & 13.50 & 9.45 & 18.90 & \\
\hline 12 & LA 2.2 & 9.00 & 6.30 & 12.60 & \\
\hline & & & \multicolumn{2}{|c|}{ Total Number of Occupants } & 142 \\
\hline
\end{tabular}

The DC and TTS for each edge have been calculated using equations (2 - 4) and are given in Table 2.

Table 2

\begin{tabular}{|c|c|c|c|c|c|c|c|c|c|}
\hline Branch & $\begin{array}{c}\text { Door } \\
\text { Width }\end{array}$ & $\begin{array}{l}\text { Effective } \\
\text { Width }\end{array}$ & $\begin{array}{c}\text { Discharge } \\
\text { Rate }\end{array}$ & $\begin{array}{c}\text { Factor } \\
\text { P/sec }\end{array}$ & $\begin{array}{l}\text { Dynamic } \\
\text { Capacity }\end{array}$ & $\begin{array}{c}\text { Travels } \\
\text { Distance }\end{array}$ & $\begin{array}{c}\text { Average } \\
\text { Speed } \\
\text { m/sec }\end{array}$ & $\begin{array}{c}\text { Total } \\
\text { Time } \\
\text { taken }\end{array}$ & $\begin{array}{l}\text { Traversal } \\
\text { time step }\end{array}$ \\
\hline \multicolumn{10}{|c|}{ Ground Floor } \\
\hline RO $1.1 \rightarrow$ CO 1.2 & 3.00 & 1.35 & 0.87 & 1.17 & 6 & 6.00 & 0.30 & 20.00 & 4 \\
\hline RO $1.1 \rightarrow$ CO 1.3 & 1.50 & 0.68 & 0.87 & 0.59 & 3 & 5.25 & 0.40 & 13.13 & 3 \\
\hline $\mathrm{CO} 1.2 \rightarrow \mathrm{CO} 1.3$ & 3.00 & 1.35 & 0.87 & 1.17 & 6 & 17.50 & 0.90 & 19.44 & 4 \\
\hline LO $1.1 \rightarrow$ CO 1.1 & 3.00 & 1.35 & 0.87 & 1.17 & 6 & 22.25 & 1.10 & 20.23 & 4 \\
\hline LO $1.1 \rightarrow$ DO 1.1 & 3.00 & 1.95 & 0.87 & 1.69 & 8 & 3.71 & 1.10 & 3.37 & 1 \\
\hline LO $1.1 \leftrightarrow$ CO 1.2 & 3.50 & 3.33 & 0.87 & 2.88 & 14 & 22.25 & 1.10 & 20.23 & 4 \\
\hline $\mathrm{CO} 1.1 \rightarrow$ DO 1.2 & 1.50 & 0.68 & 0.87 & 0.59 & 3 & 11.25 & 0.80 & 14.06 & 3 \\
\hline \multicolumn{10}{|c|}{ First Floor } \\
\hline $\mathrm{RO} 2.1 \rightarrow \mathrm{CO} 2.1$ & 4.50 & 1.58 & 0.87 & 1.37 & 7 & 4.50 & 1.10 & 4.09 & 1 \\
\hline LA $2.1 \rightarrow$ SW 2.1 & 4.50 & 1.13 & 0.87 & 0.98 & 5 & 6.00 & 0.30 & 20.00 & 4 \\
\hline SW $2.1 \rightarrow$ LO 1.1 & 4.50 & 1.13 & 0.87 & 0.98 & 5 & 3.75 & 0.15 & 25.00 & 5 \\
\hline LA $2.2 \rightarrow$ SW 2.2 & 3.00 & 0.75 & 0.87 & 0.65 & 3 & 3.75 & 0.20 & 18.75 & 4 \\
\hline SW $2.2 \rightarrow$ CO 1.3 & 1.50 & 0.45 & 0.87 & 0.39 & 2 & 2.25 & 0.10 & 22.50 & 5 \\
\hline SW $2.2 \rightarrow$ CO 1.2 & 1.50 & 0.45 & 0.87 & 0.39 & 2 & 19.75 & 0.45 & 43.89 & 9 \\
\hline
\end{tabular}

The service time and the service rate for each edge have been calculated and are given in Table 3 . The data will work as input for the model.

Table 3 Input data for model

GRAPH MATRIX :-

\begin{tabular}{|c|c|c|c|c|c|c|c|}
\hline Branch & Node-1 & Node-2 & $\begin{array}{c}\text { Type of } \\
\text { Node }\end{array}$ & $\begin{array}{l}\text { Dynamic Capacity } \\
\text { (Persons/time step) } \\
\text { (c) }\end{array}$ & $\begin{array}{c}\text { Traversal } \\
\text { Time Steps } \\
\text { (t) }\end{array}$ & $\begin{array}{c}\text { Service } \\
\text { Time }\end{array}$ & Service Rate \\
\hline 1 & 1 & 5 & 1 & 3 & 3 & 1.000 & 1.000 \\
\hline 2 & 1 & 6 & 1 & 6 & 3 & 2.000 & 0.500 \\
\hline 3 & 1 & 4 & 1 & 6 & 4 & 1.500 & 0.667 \\
\hline 4 & 4 & 5 & 1 & 6 & 4 & 1.500 & 0.667 \\
\hline 5 & 4 & 6 & 0 & 14 & 4 & 3.500 & 0.286 \\
\hline 6 & 7 & 4 & 1 & 2 & 9 & 0.222 & 4.500 \\
\hline 7 & 7 & 5 & 1 & 2 & 5 & 0.400 & 2.500 \\
\hline 8 & 8 & 7 & 1 & 3 & 4 & 0.750 & 1.333 \\
\hline 9 & 9 & 8 & 1 & 3 & 3 & 1.000 & 1.000 \\
\hline 10 & 3 & 9 & 1 & 7 & 1 & 7.000 & 0.143 \\
\hline 11 & 2 & 9 & 1 & 7 & 1 & 7.000 & 0.143 \\
\hline 12 & 9 & 10 & 1 & 3 & 3 & 1.000 & 1.000 \\
\hline 13 & 10 & 11 & 1 & 5 & 4 & 1.250 & 0.800 \\
\hline 14 & 11 & 6 & 1 & 5 & 5 & 1.000 & 1.000 \\
\hline
\end{tabular}


A Network Flow Model for Determining the Safe Evacuation Plan of a Public Building

\begin{tabular}{|l|c|c|c|c|c|c|c|}
\hline 15 & 6 & 12 & 1 & 6 & 4 & 1.500 & 0.667 \\
\hline 16 & 12 & 13 & 1 & 3 & 3 & 1.000 & 1.000 \\
\hline 17 & 5 & 13 & 1 & 3 & 1 & 3.000 & 0.333 \\
\hline 18 & 6 & 13 & 1 & 8 & 1 & 8.000 & 0.125 \\
\hline
\end{tabular}

\section{Output of the Model}

After applying the depth and breathe search technique of graph theory following paths and there 'CSR' have been computed are given in Table 4.

\begin{tabular}{|c|c|c|c|}
\hline Nodes Involve in the Path & Branch Involve in the Path & CSR & $\begin{array}{l}\text { Time of } \\
\text { Activation }\end{array}$ \\
\hline PATH - 1: 144513 & PATH - 1: 3417 & 1.667 & 9.000 \\
\hline PATH - 2: 1461213 & PATH - 2: 351516 & 2.619 & 15.000 \\
\hline PATH - 3: 14613 & PATH - 3: 3518 & 1.077 & 9.000 \\
\hline PATH - 4: 1513 & PATH - 4: 117 & 1.333 & 4.000 \\
\hline PATH - 5: 1664513 & PATH - 5: 25417 & 1.786 & 12.000 \\
\hline PATH - 6: 161213 & PATH - 6: 21516 & 2.167 & 10.000 \\
\hline PATH - 7: 1613 & PATH - 7: 218 & 0.625 & 4.000 \\
\hline
\end{tabular}

\begin{tabular}{|l|l|l|l|}
\hline Nodes Involve in the Path & Branch Involve in the Path & CSR & $\begin{array}{l}\text { Time of } \\
\text { Activation }\end{array}$ \\
\hline PATH - 8: 29874513 & PATH - 8: 11986417 & 7.976 & 22.000 \\
\hline PATH - 9: 2987461213 & PATH - 9: 1198651516 & 8.929 & 28.000 \\
\hline PATH - 10: 298874613 & PATH - 10: 11986518 & 7.387 & 22.000 \\
\hline PATH - 11: 2987513 & PATH - 11: 1198717 & 5.310 & 14.000 \\
\hline PATH - 12: 29101164513 & PATH - 12: 11 1213145417 & 4.229 & 22.000 \\
\hline PATH - 13: 29101161213 & PATH - 13: 11 1213141516 & 4.610 & 20.000 \\
\hline PATH - 14: 291011613 & PATH - 14: 11 12131418 & 3.068 & 14.000 \\
\hline
\end{tabular}

SOURCE NODE $====>3$

TOTAL NO. OF SIMPLE PATH $====>7$

\begin{tabular}{|c|c|c|c|}
\hline Nodes Involve in the Path & Branch Involve in the Path & CSR & $\begin{array}{l}\text { Time of } \\
\text { Activation }\end{array}$ \\
\hline PATH - 15: 39987744513 & PATH - 15: 10986417 & 7.976 & 22.000 \\
\hline PATH - 16: 3998774461213 & PATH - 16: 1098651516 & 8.929 & 28.000 \\
\hline PATH - 17: 398774613 & PATH - 17: 10986518 & 7.387 & 22.000 \\
\hline PATH - 18: 39877513 & PATH - 18: 1098717 & 5.310 & 14.000 \\
\hline PATH - 19: 399101116645513 & PATH - 19: 101213145417 & 4.229 & 22.000 \\
\hline PATH - 20: $3991011 \quad 61213$ & PATH - 20: 101213141516 & 4.610 & 20.000 \\
\hline PATH - 21: 391011613 & PATH - 21: 1012131418 & 3.068 & 14.000 \\
\hline
\end{tabular}

After applying the PAA of the model, the activated paths for each source node are given in Table 5.

Table-5

\begin{tabular}{|c|c|c|c|}
\hline \multicolumn{4}{|c|}{ Activated Path for Source Node -1} \\
\hline Paths & Min. Capacity & CSR & Time of Activation \\
\hline Path - 7: 1613 & 6 & 0.625 & 4.000 \\
\hline Path - 3: 14613 & 2 & 1.077 & 9.000 \\
\hline Path - 4: 1513 & 3 & 1.333 & 4.000 \\
\hline Path - 2: 14661213 & 3 & 2.619 & 15.000 \\
\hline \multicolumn{4}{|c|}{ Activated Path for Source Node -2} \\
\hline Path - 14: 291011613 & 3 & 3.068 & 14.000 \\
\hline Path - 10: 29988744613 & 2 & 5.310 & 14.000 \\
\hline Path - 11: 299875513 & 1 & 7.387 & 22.000 \\
\hline \multicolumn{4}{|c|}{ Activated Path for Source Node -3} \\
\hline Path - 21: 391011613 & 3 & 3.068 & 14.000 \\
\hline Path - 18: 3998878513 & 2 & 5.310 & 14.000 \\
\hline Path - 17: $3 \begin{array}{llllll} & 8 & 7 & 4 & 6 & 13\end{array}$ & 1 & 7.387 & 22.000 \\
\hline
\end{tabular}

Evacuation profile of occupants through the paths on each time step are given in table 6 and table 7 provide total number of occupant's use of each path. 
A Network Flow Model for Determining the Safe Evacuation Plan of a Public Building

\begin{tabular}{|c|c|c|c|c|c|c|c|c|c|c|c|}
\hline $\begin{array}{l}\text { Time } \\
\text { Step }\end{array}$ & P7 & $\mathrm{P} 4$ & P3 & $\begin{array}{c}\text { Total } \\
\text { I }\end{array}$ & P14 & P11 & $\begin{array}{c}\text { Total } \\
\text { II }\end{array}$ & P21 & P18 & $\begin{array}{c}\text { Total } \\
\text { III }\end{array}$ & $\begin{array}{c}\text { Total } \\
(\mathrm{I}+\mathrm{II}+\mathrm{III})\end{array}$ \\
\hline 1 & 0 & 0 & 0 & 0 & 0 & 0 & 0 & 0 & 0 & 0 & 0 \\
\hline 2 & 0 & 0 & 0 & 0 & 0 & 0 & 0 & 0 & 0 & 0 & 0 \\
\hline 3 & 0 & 0 & 0 & 0 & 0 & 0 & 0 & 0 & 0 & 0 & 0 \\
\hline 4 & 6 & 3 & 0 & 9 & 0 & 0 & 0 & 0 & 0 & 0 & 9 \\
\hline 5 & 6 & 3 & 0 & 9 & 0 & 0 & 0 & 0 & 0 & 0 & 9 \\
\hline 6 & 6 & 3 & 0 & 9 & 0 & 0 & 0 & 0 & 0 & 0 & 9 \\
\hline 7 & 6 & 3 & 0 & 9 & 0 & 0 & 0 & 0 & 0 & 0 & 9 \\
\hline 8 & 6 & 3 & 0 & 9 & 0 & 0 & 0 & 0 & 0 & 0 & 9 \\
\hline 9 & 6 & 3 & 2 & 11 & 0 & 0 & 0 & 0 & 0 & 0 & 11 \\
\hline 10 & 6 & 3 & 2 & 11 & 0 & 0 & 0 & 0 & 0 & 0 & 11 \\
\hline 11 & 0 & 3 & 2 & 5 & 0 & 0 & 0 & 0 & 0 & 0 & 5 \\
\hline 12 & 0 & 0 & 0 & 0 & 0 & 0 & 0 & 0 & 0 & 0 & 0 \\
\hline 13 & 0 & 0 & 0 & 0 & 0 & 0 & 0 & 0 & 0 & 0 & 0 \\
\hline 14 & 0 & 0 & 0 & 0 & 2 & 3 & 5 & 2 & 3 & 5 & 10 \\
\hline 15 & 0 & 0 & 0 & 0 & 2 & 3 & 5 & 2 & 3 & 5 & 10 \\
\hline 16 & 0 & 0 & 0 & 0 & 2 & 3 & 5 & 2 & 3 & 5 & 10 \\
\hline 17 & 0 & 0 & 0 & 0 & 2 & 3 & 5 & 2 & 3 & 5 & 10 \\
\hline 18 & 0 & 0 & 0 & 0 & 2 & 3 & 5 & 2 & 3 & 5 & 10 \\
\hline 19 & 0 & 0 & 0 & 0 & 2 & 3 & 5 & 2 & 3 & 5 & 10 \\
\hline 20 & 0 & 0 & 0 & 0 & 2 & 3 & 5 & 2 & 3 & 5 & 10 \\
\hline TOTAL & 42 & 24 & 6 & 72 & 14 & 21 & 35 & 14 & 21 & 35 & 142 \\
\hline
\end{tabular}

Table 7

\begin{tabular}{|c|c|c|c|}
\hline Paths & $\begin{array}{l}\text { Total number of occupants } \\
\text { moving through the path }\end{array}$ & $\begin{array}{c}\text { Required Traversal } \\
\text { Time Step (TTS) }\end{array}$ & $\begin{array}{c}\text { Total Time of evacuation of the } \\
\text { building }\end{array}$ \\
\hline Path - 7: 1613 & 42 & \multirow{3}{*}{11} & \multirow{10}{*}{$\begin{array}{l}1 \mathrm{TP}=5 \text { Seconds, therefore } \\
20 \times 5=100.00 \text { Seconds }\end{array}$} \\
\hline Path - 4: 1513 & 24 & & \\
\hline Path - 2: 14461213 & 00 & & \\
\hline Source Node 2 & & & \\
\hline Path - 10: 22988744613 & 21 & \multirow[t]{2}{*}{09} & \\
\hline Path - 11: 29987513 & 00 & & \\
\hline \multicolumn{3}{|l|}{ Source Node 3} & \\
\hline Path - 21: 391011613 & 14 & \multirow{3}{*}{09} & \\
\hline Path - 18: 399877513 & 21 & & \\
\hline Path - 17: $\begin{array}{lllllll}3 & 9 & 8 & 7 & 4 & 6 & 13\end{array}$ & 00 & & \\
\hline
\end{tabular}

The throughput 'TP' and expected number of occupants in the activated paths have been calculated by using equations (9) and (10) respectively. The expected queue length of the occupants passing through the activated paths has also been computed using equation (11). The required mean waiting time of the occupants in the queue and the expected waiting time of the occupants in the paths have been calculated using equation (12) and (13) respectively. The results are shown in Table 8.

Table 8

\begin{tabular}{|c|c|c|c|c|c|c|c|c|}
\hline Paths & Service Rate & \multicolumn{2}{|c|}{$\begin{array}{l}\text { Arrival and } \\
\text { Service Rate }\end{array}$} & $\begin{array}{l}\text { Throughput of } \\
\text { the Paths }\end{array}$ & \multicolumn{2}{|c|}{$\begin{array}{l}\text { Expected number of } \\
\text { Occupants in the } \\
\text { queue and expected } \\
\text { queue length }\end{array}$} & \multicolumn{2}{|c|}{$\begin{array}{l}\text { Mean waiting time in the queue and } \\
\text { expected waiting time of the } \\
\text { Occupants in the paths }\end{array}$} \\
\hline Path -7 & 0.625 & 1.600 & 6 & 6.000 & 0.364 & 0.097 & 0.061 & 0.227 \\
\hline Path -4 & 1.333 & 0.750 & 3 & 3.429 & 0.333 & 0.083 & 0.111 & 0.444 \\
\hline Path - 3 & 1.077 & 0.929 & 2 & 2.000 & 0.867 & 0.402 & 0.433 & 0.933 \\
\hline Path - 11 & 5.310 & 0.188 & 2 & 3.000 & 0.104 & 0.010 & 0.052 & 0.552 \\
\hline Path - 21 & 3.068 & 0.326 & 3 & 2.000 & 0.122 & 0.013 & 0.041 & 0.374 \\
\hline Path - 18 & 5.310 & 0.188 & 2 & 3.000 & 0.104 & 0.010 & 0.052 & 0.552 \\
\hline
\end{tabular}

Table- 8 shows that the paths of the building network are activated in such a way that the person gets the service according to their arrival rate which is depicted in Fig.3. 


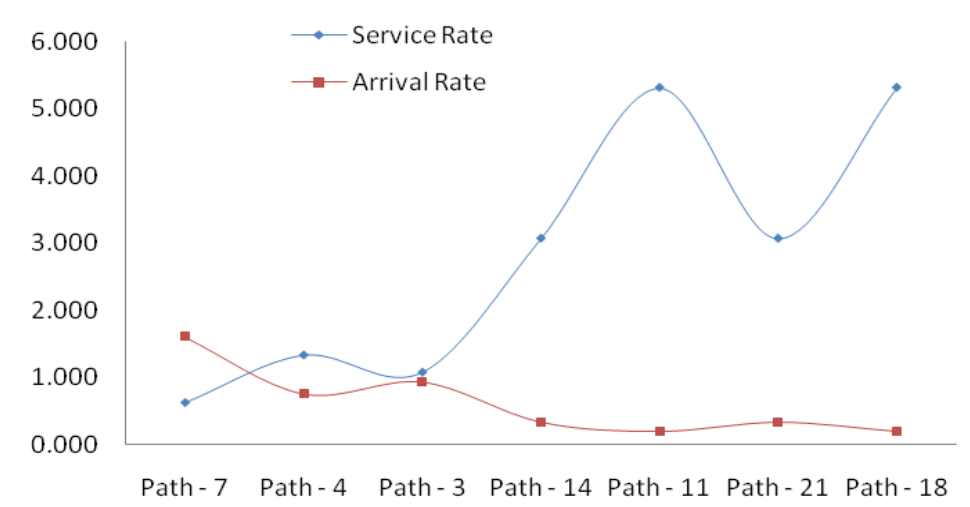

Fig.3 Relation between arrival rate and service rate

It is observed that there is a relation between the expected queue length and the mean and expected waiting time in the queue. It is also observed that the mean waiting time in the queue and expected waiting time in the activated path are directly related to each other which are depicted in Fig.4.

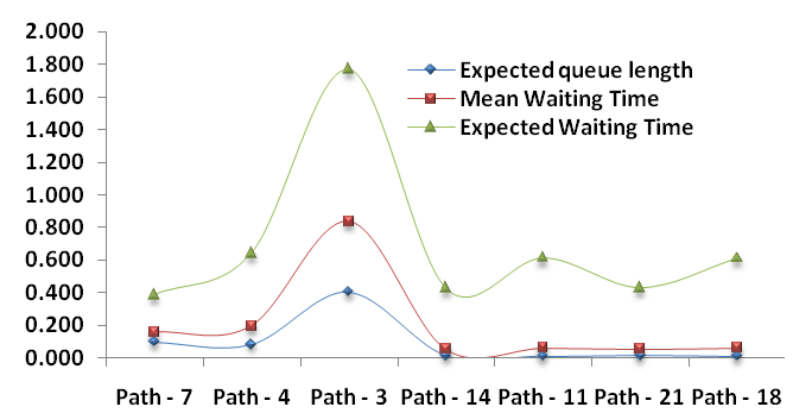

Fig.4 Mean and expected waiting time and expected queue length

From the study it may be concluded that the response time and throughput of the paths are inversely proporsnal to each other i.e. the throughput is higher for those paths which give response early and vice versa. This is depicted in Fig. 5.

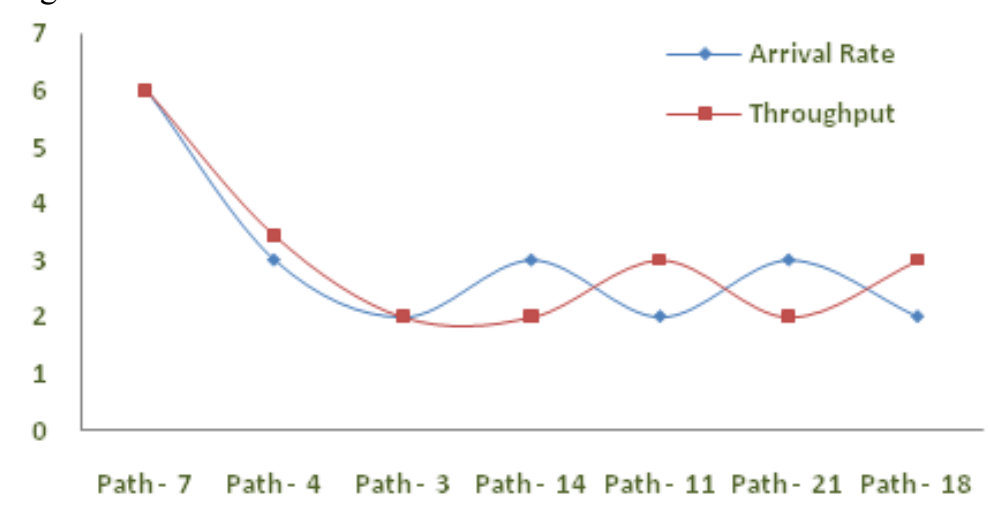

Fig.5 Relation between throughput and arrival rate of the activated paths

\section{Conclusions}

In the present paper a simple and efficient mathematical model has been presented, which is the extension of our previous model SAFE-R. A simple equation has been presented to determine the number of people traveling through a path / route. An example building has been considered to exemplify the usefulness of the present model and compared with the results of SAFE-R and EVACNET4. The total evacuation time determined by the SAFE-R is 105 s and 115 s by EVACNET4 for evacuating the 142 occupants, whereas, the time computed by the present model is 100 s. 


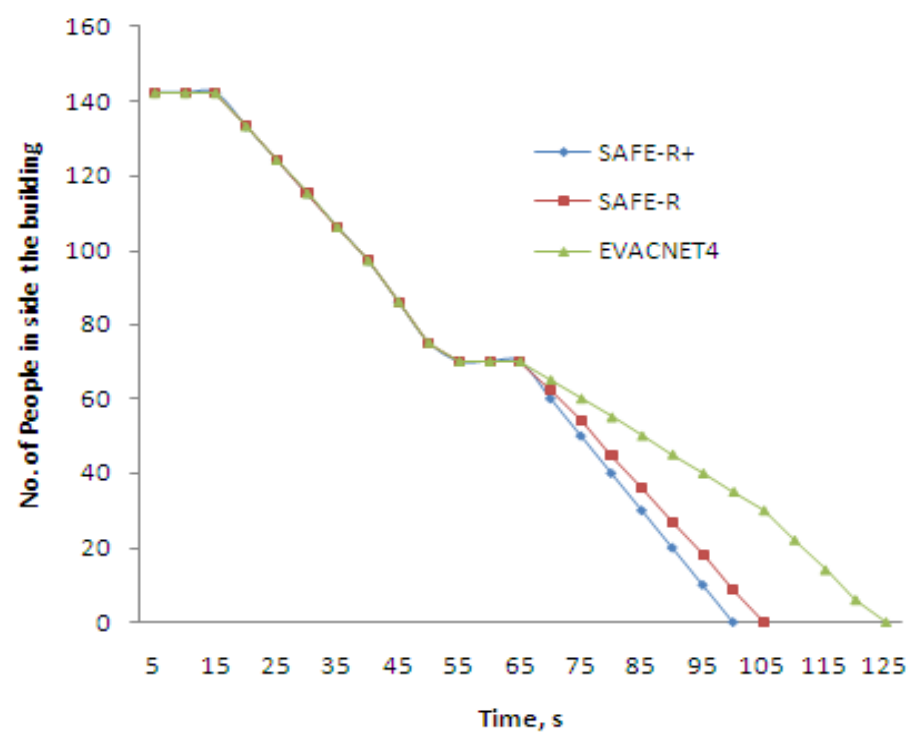

Table 5 shows the activated paths, which have been used by the evacuees to evacuate the building. The actual evacuation process started only after $15 \mathrm{~s}$ this is due to the activation time of the paths $1,3,6,11$. The path 4 activates after 30 s and starts the evacuation process.

Table 8 give the scenario about the throughput and expected number of occupants in the activated paths in a building network and the expected queue lengths of the occupants passing through the activated paths. The required mean waiting time and expected waiting time of the occupants in the queue for all activated paths queue have also been given in Table 8 .

This model is very useful at the time of planning a residential/commercial complex. Plans may be modified for the minimum evacuation time and safe exit. The model is also suitable to train the occupants for efficient evacuation without congestion and bottlenecks.

The present model is useful to make relative comparisons between several alternatives to find an optimal egress plan and to decide the permissible value of travel distance as well as the time of evacuation. The occupants can be trained beforehand to undergo regular practice so that the egress goes well during emergencies.

\section{Acknowledgement}

Authors are thankful to Director, CBRI, for his keen interest in the present work. This paper is published with kind permission of Director CSIR - CBRI, Roorkee.

\section{References}

[1] I. Furin, Pedestrian planning and design, Metropolitan association of urban designers and environmental planners, New York, 1971

[2] L.G. Chalmet, R.L Francis and P.B. Saunders, Network Models For Building Evacuation, Management Science, Vol. 28, No. 1, pp. 86-105, January, 1982.

[3] R,L Francis, and L.G. Chalmet, A Negative Exponential Solution To An Evacuation Problem, Research Report No. 84-86, National Bureau of Standards, Center for Fire Research, Washington DC, 20234, October, 1984.

[4] T.M. Kisko, and R.L. Francis, EVACNET+: A Computer Program to Determine Optimal Building Evacuation Plans, Fire Safety Journal, 9:211-222, 1985.

[5] M.Y. Roytman, Principles of Fire Safety Standards for Building Construction, published for the National Bureau of Standards, Washington, DC By Amerind Publishing Co., Pvt. Ltd. New Delhi, India, 1975.

[6] V.M. Predtechenskii and A.I. Milinskii, Planning for foot traffic flow in buildings, New Delhi, Amerind publishing co. pvt. Ltd., 1978.

[7] A.K. Gupta \& P.K. Yadav, SAFE-R: A New Model to Study the Evacuation Profile of a Building, Fire Safety Journal Vol 29(7), 2004, pp 539-556

[8] A.K. Gupta, P.K.Yadav, \& R.K. Sharma, Evacuation Management in High Rise Buildings, Presented and published in national seminar on High Rise Buildings: Material and Practices Organised by Indian Society for Construction Material and Structures, IIT Campus Roorkee, held at Le MEDRIEN Hotel Delhi during 30 -31 October. 2006, pp 473-482

[9] R,L Francis, and L.G. Chalmet, Network Models for Building Evacuation: A Prototype Primer, NBS-GCR-81-316, National Bureau of Standards, Center for Fire Research, Washington DC, 20234, March, 1981.

[10] R,L Francis, and L.G. Chalmet, Network Models for Building Evacuation: Development of Software System, NBS-GCR- $\quad 84-$ 457, National Bureau of Standards, Center for Fire Research, Washington DC, 20234, May, 1984.

[11] W.E Pucci, Hot Software for the Fire Protection Community, NFPA Journal, January/February, 1997 , pp. 51-56.

[12] F.R. Fahy, Exit89 -An evacuation model for high-rise buildings -model description and example applications, Fire Safety Science Proceedings of the fourth international symposium 1994, pp. 657-668.

[13] P.A. Thompson, and E.W. Marchant, SIMULEX; Developing new computer modelling techniques for evaluation, Fire Safety Science -Proceedings of the fourth international symposium 1994, pp. 613-624. 
[14] P.A. Thompson, and E.W. Marchant, A Computer Model for the evacuation of Large Building Populations, Fire Safety Journal, 1994; vol. 24, pp. 131-148

[15] P.A. Thompson, and E.W. Marchant, Testing and Application of the Computer Model SIMULEX, Fire Safety Journal, 1994 vol. 24, pp. 149-166.

[16] I. Hagiwara, and T. Tanaka, International Comparison of Fire Safety Provision for Means of Escape, Fire Safety Science Proceedings of the fourth international symposium 1994, p. 633-644.

[17] G.N. Berlin, A. Dutt, and S.M. Gupta., Modeling emergency evacuation from group homes, Fire Technology 1982; pp. 18-38 